\title{
In Vitro Characterization of an Avian Reovirus Vaccine Strain
}

\author{
VERA GOUVEA,* DIANA D. HUANG, $\uparrow$ TERESA RAMOS,$\dagger$ \\ AND THOMAS J. SCHNITZER ${ }^{*}+$,
}

\begin{abstract}
*Department of Epidemiology, School of Public Health, and + Rackham Arthritis Research Unit, Department of Internal Medicine, School of Medicine, University of Michigan, Ann Arbor, Michigan 48109
\end{abstract}

Received October 13, 1982; accepted December 13, 1982

\begin{abstract}
In vitro studies were performed to characterize the vaccine strain, designated P100, derived from the arthrogenic reovirus isolate, $\mathrm{S} 1133$, by cold adaptation. P100 appeared to be temperature sensitive, shown by a marked drop in titer and efficiency of plaquing after incubation at $41^{\circ}$. Studies indicated that genomic double-stranded RNA and protein synthesis were severely restricted at the elevated temperature. Differences in the growth behavior of $\mathrm{P} 100$ and $\mathrm{S} 1133$ at $37^{\circ}$ were also noted. The vaccine strain seemed to be more cell associated than S1133. Three outer coat proteins of P100 grown at $37^{\circ}$ displayed mobilities different from those of $\mathrm{S} 1133$ by PAGE. It is possible that alterations in these proteins may have some relationship to the growth characteristics observed for the P100 strain.
\end{abstract}

\section{INTRODUCTION}

Reoviruses are ubiquitous in nature, possessing a wide range of hosts including man, numerous other mammals, and domestic birds (Ramig and Fields, 1977). The avian reoviruses comprise a serologically distinct group that can be differentiated further from the mammalian reoviruses by their lack of a hemagglutinin, different host range, and ability to fuse cells in culture (Olson, 1978). Moreover, unlike the mammalian reoviruses, avian reoviruses have been naturally associated with a variety of diseases including viral arthritis and tenosynovitis, gastroenteritis, hepatitis, myocarditis, and respiratory illness in chickens (van der Heide, 1980) and infectious enteritis in turkeys (Gershowitz and Wooley, 1973).

Viral arthritis in chickens, first recognized in 1959 (Olson, 1959), has since received great attention from researchers in the poultry industry. The disease, although associated with low mortality, often produces high morbidity rates resulting in significant economic losses (Glass et $a l ., 1973$; Olson and Solomon, 1968) and

${ }^{1}$ To whom reprint requests should be directed. therefore attempts have been made to produce a vaccine suitable for young chicks. Continued in vitro propagation at $31^{\circ}$ of an extremely virulent and arthrogenic isolate, S1133, was performed and the resulting pools were tested at various levels of passage for efficacy in terms of immunogenicity and protection afforded upon challenge with wild-type virus (Rau et al., 1980; van der Heide, 1975; van der Heide, 1980). A vaccine has been produced from the 100th passage virus pool and designated "P100." Pathogenicity of P100, when given by different routes of inoculation and at various doses to day-old chicks, has been studied and compared to the parent S1133 (Gouvea and Schnitzer, 1982).

The conditions under which strain S1133 was serially propagated in order to obtain P100 were those of "cold-adaptation." However, the manner in which P100 differs from the parental S1133 has not been examined in vitro. The relative ability of P100 to grow at either low or high temperature has not been evaluated nor have any biochemical studies looked for alterations in viral proteins or genes. The aim of this study was to undertake an initial in vitro characterization in biological and 
biochemical terms of the vaccine strain P100 in an attempt to detect differences from the parent S1133. Further examination of such alterations could then help identify genetic and biochemical markers that may be useful for studies on factors related to viral virulence in chickens.

\section{MATERIALS AND METHODS}

Cells. Chick embryo fibroblasts (CEF) and chick embryo liver cultures (CELi) were prepared from 10- and 14-day-old embryos, respectively, by conventional tissue culture techniques. CEF cells were grown in Dulbecco's modified essential medium (DMEM) supplemented with $5 \%$ tryptose phosphate broth, $2 \%$ newborn calf serum (NCS), and $2 \%$ chick serum. The first and second passages of CEF grown in the same medium were used for virus propagation. CELi cultures were prepared in DMEM supplemented with $10 \%$ NCS and used within 48 to $72 \mathrm{hr}$.

Viruses. The 73rd chorioallantoic membrane (CAM) passage of strain S1133 of avian reovirus, originally isolated during an outbreak of severe tenosynovitis in Connecticut, and its attenuated vaccine strain P100 (van der Heide, 1975, 1980) were kindly supplied by Dr. L. van der Heide (Department of Pathobiology, University of Connecticut, Storrs). The P100 virus had been produced by 235 passages in CAM followed by an additional 100 passages in CEF, 40 of which were at low temperature $\left(32^{\circ}\right)$ (L. van der Heide, personal communication). Both S1133 and P100 viruses were plaque-purified three times in $\mathrm{CEF}$ and a final pool was made and titrated to be used in all assays.

Virus titration. CEF or CELi monolayers grown in six-well plastic plates were infected with $0.5 \mathrm{ml} /$ well of a series of 10 fold dilutions of virus suspension in phosphate-buffered saline (PBS) and virus allowed to absorb at $37^{\circ}$ for $1 \mathrm{hr}$. The inoculum was then removed and the cells were washed twice with PBS. Two milliliters of overlay medium $(1.5 \%$ agarose, $2 \%$ NCS in minimum essential (MEM)) was added per well and plates were incubated at $37^{\circ}$. When plaques could be eas- ily detected, after 2 days (CELi) or 4 days (CEF), $1 \mathrm{ml}$ of a second overlay $(0.9 \%$ agarose, $0.005 \%$ neutral red in MEM) was added per well. Plates were incubated at $37^{\circ}$ and plaques were counted on the next day.

Efficiency of plaquing (EOP) at 33 and $41^{\circ}$. Determination of the ability of the viruses to produce plaques at high and low temperatures was done as described above for virus titration, except that after adsorption at $37^{\circ}$, plates were incubated at 33,37 , or $41^{\circ}$ accordingly.

Propagation and protein labeling of viruses. Confluent monolayers of CEF cells in $90-\mathrm{mm}$ plates were infected with $0.5 \mathrm{ml}$ of virus suspension at a multiplicity of infection (m.o.i.) of approximately 1 , and incubated at $37^{\circ}$ for $1 \mathrm{hr}$. After virus adsorption, the inoculum was removed, $5 \mathrm{ml}$ of DMEM-2\% NCS was added per plate, and the plates were returned to $37^{\circ}$. When CPE became evident, but infected cells were still attached to the plate, the medium was replaced with DMEM containing $5 \%$ the normal amount of methionine and $2 \%$ dialyzed NCS. Then $100 \mu \mathrm{Ci}$ of $\left.{ }^{35} \mathrm{~S}\right]$ methionine (Amersham, $400-800 \mathrm{Ci} /$ mol) was added per plate and virus multiplication allowed to proceed at $37^{\circ}$. At maximum CPE, usually $48 \mathrm{hr}$ postinfection (p.i.), infected cultures were harvested and either frozen at $-70^{\circ}$ or immediately processed for virus purification.

Purification of virus. Cellular and supernatant fractions from infected cultures were separated by low-speed centrifugation. Virus was recovered from the supernatant by pelleting, pooled with cellular fraction, extracted with Freon, and purified by $\mathrm{CsCl}$ gradient centrifugation as previously described (Schnitzer et al, 1982).

Radiolabeling and immune precipitation of viral proteins in cell extracts. CEF cells in $60-\mathrm{mm}$ plates were infected at a m.o.i. of $10 \mathrm{PFU} /$ cell as described above and incubated either at 37 or $41^{\circ}$. At various times after adsorption, metabolic labeling was done by replacing the medium with methionine-free medium containing $2 \%$ dialyzed NCS and supplemented with 25 $\mu \mathrm{Ci}$ of $\left[{ }^{35} \mathrm{~S}\right]$ methionine $/ \mathrm{ml}$. After a $3-\mathrm{hr}$ pulse, a cellular extract was prepared and 
viral polypeptides were immunoprecipitated as previously described (Schnitzer et $a l ., 1982$ ).

Radiolabeling of cytoplasmic $d s R N A$. CEF monolayers in 50-mm plates were infected at a m.o.i. of $10 \mathrm{PFU} /$ cell and incubated at $37^{\circ}$ for $1 \mathrm{hr}$. After adsorption the inoculum was removed and $3 \mathrm{ml}$ of DMEM containing $2 \%$ dialyzed NCS, 60 $\mu \mathrm{g} / \mathrm{ml}$ actinomycin $\mathrm{D}$ (Act. D), and $30 \mu \mathrm{Ci}$ [5-6- $\left.{ }^{3} \mathrm{H}\right]$ uridine (Amersham) were added per plate and the plates incubated either at 37 or $41^{\circ}$ in a $5 \% \mathrm{CO}_{2}$ atmosphere. At $18 \mathrm{hr}$ postinfection the cells were harvested and separated from the supernatant by low-speed centrifugation. Virus was pelleted from the supernatant by centrifugation at $50,000 \mathrm{~g}$ for $90 \mathrm{~min}$ and solubilized in Laemmli's sample buffer. Cytoplasmic double-stranded RNA (dsRNA) and cell-associated virus in the cellular fraction were dissolved in Laemmli's sample buffer.

Polyacrylamide gel electrophoresis. Electrophoresis was carried out in $9 \%$ acrylamide- $0.267 \%$ bis-acrylamide slab gels in a discontinuous Tris-glycine buffer system. Samples were boiled for $1 \mathrm{~min}$ prior to loading onto gels, and electrophoresis proceeded at $140 \mathrm{~V}$ for $15 \mathrm{hr}$ (dsRNA) or at $200 \mathrm{~V}$ for $4 \mathrm{hr}$ (proteins). After the run, gels were fixed and processed for autoradiography as previously described (Gouvea and Schnitzer, 1982) or silver stained as described by Sammons et al. (1981).

\section{RESULTS}

Growth characteristics. Representative growth curves of virus strains S1133 and P100 incubated at 33,37 , and $41^{\circ}$ in CEF cclls are shown in Fig. 1. It can be seen that $\mathrm{S} 1133$ replicated well at all three temperatures, with peak virus production occurring at $18 \mathrm{hr}$ p.i. The $\mathrm{P} 100$ strain yielded titers similar to those of S1133 after incubation at $37^{\circ}$, while appearing to generate slightly more progeny than S1133 at $33^{\circ}$. However, in marked contrast to S1133, P100 seemed unable to multiply at $41^{\circ}$. The efficiency of plating (EOP) of both viral strains at 33 and $41^{\circ}$ was determined (Table 1), demonstrating that P100 had also acquired a temperature-sensitive $(t s)$ characteristic in the process of becoming cold adapted. At either 33 or $37^{\circ}$, the plaque morphologies of both strains were indistinguishable. Both viruses produced extensive syncytia with complete destruction of the monolayer, although the syn-

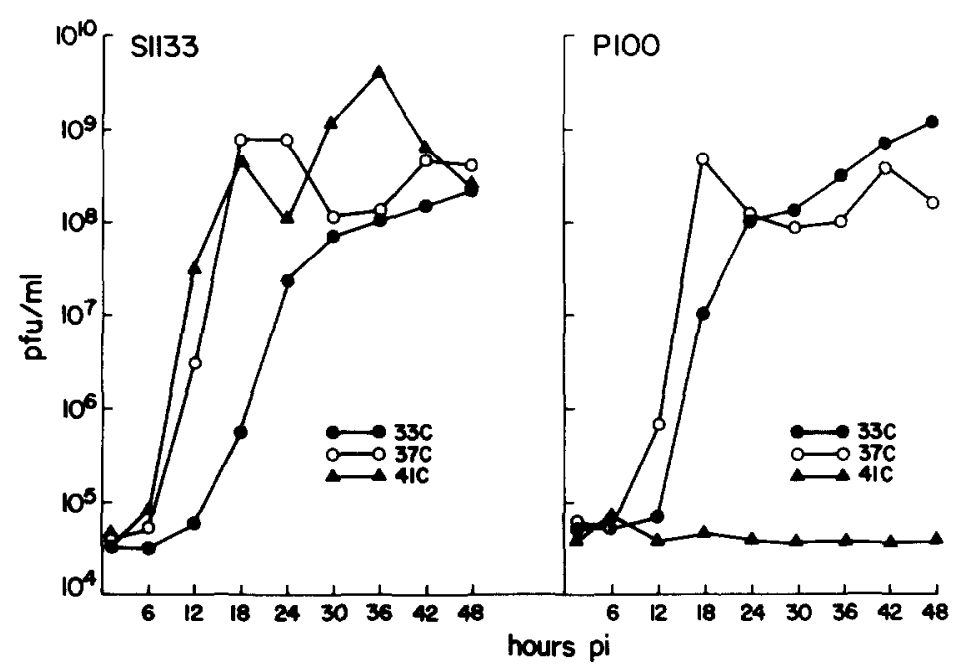

FIG. 1. Growth curves of $\mathrm{S} 1133$ and $\mathrm{P} 100$ at 33, 37, and $41^{\circ}$. CEF monolayers in 30-mm plates were infected at an m.o.i. of $2 \mathrm{PFU} /$ cell. After virus adsorption for $1 \mathrm{hr}$ at $37^{\circ}$, the cells were washed twice with PBS and $2 \mathrm{ml}$ of DMEM $-2 \%$ NCS was added. Plates were incubated at 33, 37, or $41^{\circ}$. Every $6 \mathrm{hr}$ duplicate plates were withdrawn from each incubator, submitted to three cycles of freeze-thawing, and the culture suspensions were titrated in CELi monolayers incubated at $37^{\circ}$. 
TABLE 1

EFficiency of Plaquing (EOP) at 33 and $41^{\circ}$

\begin{tabular}{llllr}
\hline & & \multicolumn{3}{c}{$\begin{array}{c}\text { Virus titer } \\
\end{array}$} \\
\cline { 3 - 5 } Virus & Cells & $33^{\circ}$ & $37^{\circ}$ & $41^{\circ}$ \\
\hline S1133 & CEF & 6.3 & 7.2 & 6.9 \\
& CELi & 6.8 & 7.8 & 6.8 \\
P100 & CEF & 7.0 & 6.5 & $<2.0$ \\
& CELi & 7.9 & 7.5 & $<2.0$ \\
\hline
\end{tabular}

${ }^{a}$ Numbers represent the mean of titers obtained in 3 experiments.

cytia in S1133-infected cultures were often significantly larger than those obtained in P100-infected cultures.

Another difference in the behavior of the two strains is emphasized in Table 2. Viral titers obtained at various times after infection from the supernatant of either S1133- or P100-infected cells or from the harvested cell monolayers themselves suggested that P100 particles may be more cell associated than $\mathrm{S} 1133$ particles. The titers show that up to $24 \mathrm{hr}$ p.i. the yields of the parent strain, S1133, from the supernatant and the cells follow a similar distribution to that seen in the P100-infected cultures with approximately 100fold more virus being found in the cellular fraction than in the supernatant. However, by $37 \mathrm{hr}$ p.i. and after, this pattern was changed. In the S1133-infected cul- tures, roughly equal amounts of virus were shed into the supernatant as were found in the cellular portion of the cultures; in the P100 infections, 100 - to 1000 -fold more virus was recovered from the cell monolayers than from the supernatant.

Synthesis of genomic dsRNA. Although the P100 strain seemed unable to form infectious progeny at $41^{\circ}$, it was of interest to determine whether any phase of viral replication was taking place within the host cells at the restrictive temperature. CEF cultures infected with $\mathrm{P} 100$ in the presence of Act. $\mathrm{D}$ were incubated at $41^{\circ}$ and labeled with $\left[{ }^{3} \mathrm{H}\right]$ uridine to see if any genomic dsRNA was synthesized. The autoradiogram in Fig. 2 shows that P100 segments are not present in infected cell lysates after incubation at the restrictive temperature. By subjecting the gel to the more sensitive assay of silver staining, faint bands could be detected which migrated parallel to the genomic segments synthesized during a productive infection (data not shown). These data indicate that a very limited level of $\mathrm{P} 100$ replication may take place at the nonpermissive temperature, although the infection is largely inhibited.

The dsRNA segments extracted from supernatant or cell monolayers infected with $\mathrm{P} 100$ at $37^{\circ}$ migrated identically to those of S1133 analyzed in a similar manner (Fig. 2). There was no evidence of either smaller genomic fragments or dele-

TABLE 2

Titers of P100 and S1133 Obtained from Supernatant and Cellular Fractions of INFECTED CULTURES INCUBATED AT $37^{\circ} a$

\begin{tabular}{|c|c|c|c|c|c|c|}
\hline \multirow[b]{2}{*}{ hr p.i. } & \multicolumn{3}{|c|}{$\mathrm{S} 1133$} & \multicolumn{3}{|c|}{ P100 } \\
\hline & $\begin{array}{c}\mathrm{PFU} / \mathrm{ml} \\
\text { supernatant }\end{array}$ & $\begin{array}{l}\mathrm{PFU} / \mathrm{ml} \\
\text { cells }\end{array}$ & $\begin{array}{c}\text { Total } \\
\text { PFU/ml }\end{array}$ & $\begin{array}{c}\mathrm{PFU} / \mathrm{ml} \\
\text { supernatant }\end{array}$ & $\begin{array}{l}\mathrm{PFU} / \mathrm{ml} \\
\text { cells }\end{array}$ & $\begin{array}{c}\text { Total } \\
\text { PFU } / \mathrm{ml}\end{array}$ \\
\hline 2 & $2.3^{b}$ & 2.6 & 2.8 & 2.9 & $<2.0$ & 2.9 \\
\hline 7 & 2.3 & 2.6 & 2.8 & 2.9 & $<2.0$ & 2.9 \\
\hline 12 & 2.7 & 4.6 & 4.6 & 2.0 & 2.3 & 2.4 \\
\hline 18 & 2.9 & 5.0 & 5.0 & 2.0 & 3.4 & 3.4 \\
\hline 24 & 4.3 & 6.0 & 6.0 & 2.6 & 4.0 & 4.0 \\
\hline 37 & 6.8 & 7.7 & 7.8 & 4.0 & 7.0 & 7.0 \\
\hline 42 & 8.0 & 7.7 & 8.1 & 4.1 & 7.0 & 7.0 \\
\hline 52 & 7.3 & 7.0 & 7.5 & 5.7 & 7.3 & 7.3 \\
\hline
\end{tabular}

\footnotetext{
${ }^{a}$ Supernatant fractions refer to medium alone before the monolayer was harvested. The monolayer was then subjected to 3 cycles of freeze-thawing before sonication. Infection was initiated at an m.o.i. of 2-5.

${ }^{b}$ Numbers are expressed as $\log _{10} \mathrm{PFU} / \mathrm{ml}$.
} 


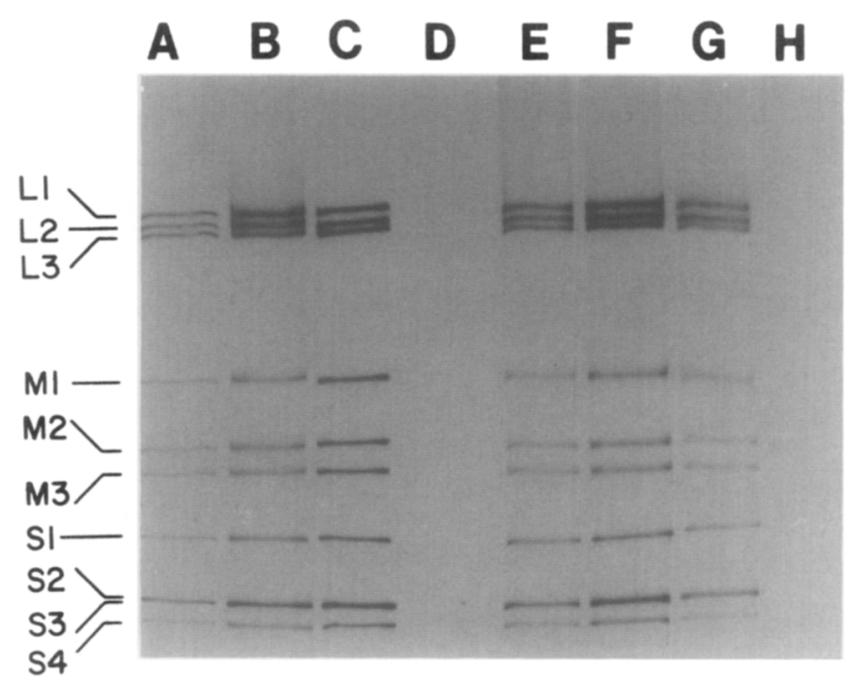

FIG. 2. $\left[{ }^{3} \mathrm{H}\right]$ Uridine-labeled dsRNA of S1133 and P100. Supernatant virus dsRNA of S1133 produced at 37 (A) and $41^{\circ}(\mathrm{B})$, and of P100 produced at 37 (C) and $41^{\circ}$ (D). Cytoplasmic and cell-associated viral dsRNA from cellular fraction of S1133-infected cells synthesized at $37(\mathrm{E})$ and $41^{\circ}(\mathrm{F})$, and of P100-infected cells synthesized at $37(\mathrm{G})$ and $41^{\circ}(\mathrm{H})$.

tion of entire genome segments to suggest DI particle formation during infection. Similar results were seen after S1133 infection at either 37 or $41^{\circ}$. In addition, there was no detectable difference in the mobilities of the S1133 or P100 segments, an observation which has been previously reported (Gouvea and Schnitzer, 1982).

Synthesis of viral proteins. Infection with the P100 strain at $41^{\circ}$ was also examined for any evidence of viral protein synthesis. Cultures were pulse-labeled with $\left[{ }^{35} \mathrm{~S}\right]-$ methionine at various times after infection. At the end of the labeling period, cell lysates were prepared and proteins immune-precipitated to determine which, if any, viral proteins could be synthesized at the nonpermissive temperature. Figure 3 depicts the results of one such experiment. The gel patterns indicate that only trace amounts of some of the proteins of P100 are synthesized after incubation at $41^{\circ}$ in comparison to the profile seen after growth at $37^{\circ}$. Although only proteins $\mu_{\mathrm{B}}, \sigma_{\mathrm{A}}$, and $\sigma_{\mathrm{C}}$ appear most clearly, it is not possible to say that the other proteins are not being produced. It can be noted that all the S1133 proteins are present in large quantities after infection at either 37 or $41^{\circ}$. Results similar to those obtained from infected CEF cultures are seen when Vero cells are

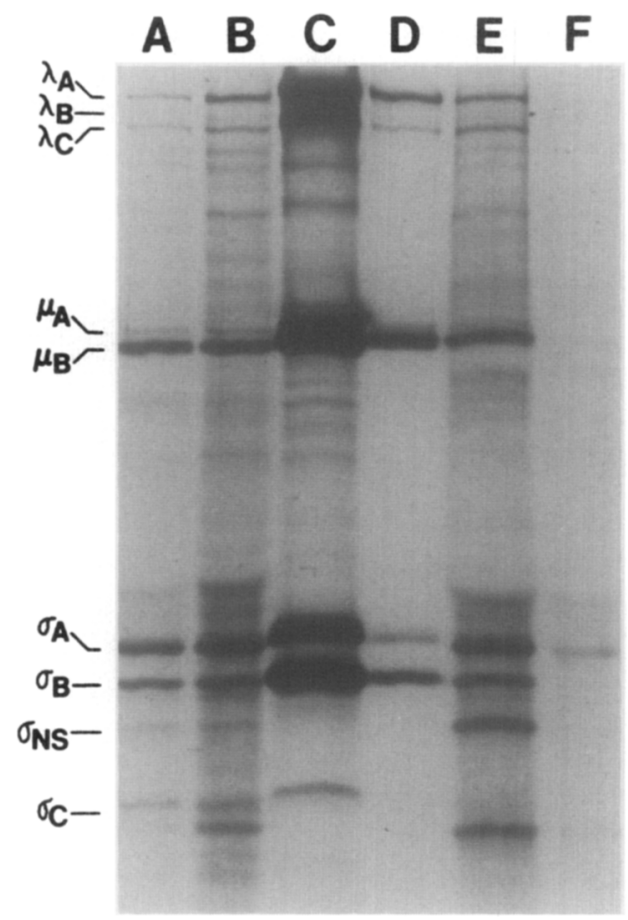

Fig. 3. Autoradiogram of $\left[{ }^{35} \mathrm{~S}\right]$ methionine-labeled polypeptides of $\mathrm{S} 1133$ and $\mathrm{P} 100$. Cell extracts from S1133-infected cells incubated at 37 (A) and at $41^{\circ}$ (B), and of P100-infected cells incubated at 37 (E) and at $41^{\circ}$ (F) were pulse-labeled ( $3 \mathrm{hr}$ ) at $12 \mathrm{hr}$ p.i. and subjected to immune precipitation. Comparison was made with CsCl-purified S1133 (C) and P100 (D) viruses. 


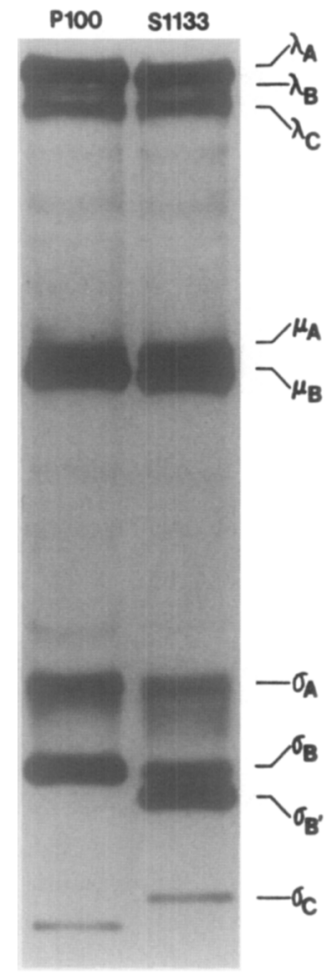

FIG. 4. Autoradiogram of $\left[{ }^{35} \mathrm{~S}\right] \mathrm{methionine-labeled}$ structural polypeptides of $\mathrm{S} 1133$ and P100-purified viruses. Note the additional $S 1133$ polypeptide $\sigma_{\mathrm{B}}$, a degradation product of polypeptide $\sigma_{\mathrm{B}}$.

infected with S1133 or P100 at either temperature (data not shown) suggesting that the severe decrease in synthesis of P100 polypeptides at $41^{\circ}$ is not a host-cell-dependent phenomenon.

Comparison of the polypeptides of $S 1133$ and P100 strains. When the proteins of P100 and S1133 are examined by PAGE, it can be seen that at least two polypeptides of P100 have mobilities which differ from those of the parental S1133 (Figs. 3 and 4 ). The major $\mu$ polypeptide, $\mu_{\mathrm{B}}$, appeared to have a slightly slower migration, while a minor $\sigma$ protein, $\sigma_{\mathrm{C}}$, ran well ahead of the $\mathrm{S} 1133 \sigma_{\mathrm{C}}$. Both these avian reovirus polypeptides have been identified as outer capsid proteins (Schnitzer et al., 1982). In addition, repeated examination of the proteins of the same preparation of purified S1133 revealed that upon prolonged storage or repeated freeze-thawing cycles, there was a gradual degradation of the $\sigma_{\mathrm{B}}$ polypeptide yielding a new, lower-molecular-weight protein $\sigma_{\mathrm{B}^{\prime}}$ (Fig. 4). This oc- curred repeatedly with several different preparations of $\$ 1133$. However, preparations of purified $\mathrm{P} 100$, treated in the same manner, seldom generated this fragment, and when $\sigma_{\mathrm{B}^{\prime}}$ was seen it appeared in much lesser proportions than the $\sigma_{\mathrm{B}^{\prime}}$ of $\mathrm{S} 1133$. The other P100 proteins appeared identical to those of S1133.

\section{DISCUSSION}

The data presented show that the avian rcovirus vaccine strain, $\mathrm{P} 100$, has acquired some growth characteristics which are not seen in its parental strain, S1133. In the process of becoming cold-adapted, $\mathrm{P} 100$ has also become temperature sensitive at $41^{\circ}$, demonstrated by the inability of the virus to multiply or plaque at this temperature. Although cold adaptation and temperature sensitivity are independent properties, as has been shown with many chemically mutagenized viruses, it is not uncommon for viruses adapted to grow at a lower temperature to simultaneously acquire the ts characteristic (Maassab et al., 1981).

The analysis of the growth behavior and synthesis of viral genome and proteins indicates that S1133 grows equally well at normal $\left(37^{\circ}\right)$ and "restrictive" temperatures $\left(41^{\circ}\right)$. However, the $P 100$ strain appears severely limited in its ability to replicate at the higher temperature. Minute amounts of genomic dsRNA were detectable only by silver staining and not by autoradiography, and only trace amounts of, at most, three viral proteins could be found by immunoprecipitation after infection at $41^{\circ}$. These observations would suggest that P100 can enter the host cell and is presumably uncoated, permitting initiation of viral replicative events and limited protein synthesis. Amplification of viral replication seems to be restricted afterward, evidenced by the low virus yields at the elevated temperature. It is not possible to determine which defective viral functions contribute to this inhibition.

Acquisition of the $t s$ trait in numerous instances has occurred spontaneously, oftentimes accompanied by a loss of virulence. P100 has been demonstrated to be much less virulent for day-old chicks than S1133 (Gouvea and Schnitzer, 1982). Yet 
the same experiments demonstrated that lack of virulence is not a reflection of decreased infectivity. $P 100$ virus was still able to infect, spread, localize, and multiply in target tissues. It is worth noting that $41^{\circ}$, the in vitro restrictive temperature for P100 virus, is the physiological temperature of the chicken. It is possible, though, that sites with slightly lower body temperature would permit at least low levels of P100 viral replication. Site-specific attenuation has been documented for infections with $t s$ mutants of influenza and respiratory syncytial virus (Murphy et al., 1972; Wright et al., 1971).

Differences in behavior between $\mathrm{P} 100$ and $\mathrm{S} 1133$ have also been noted at $37^{\circ}$. There is an indication that $\mathrm{P} 100$ is not capable of shutting off the host as well as the wild-type S1133 (unpublished results). Another interesting observation is that P100 appears to remain cell associated at $37^{\circ}$ while $\mathrm{S} 1133$ particles are released. These functional changes could relate to the decreased pathogenicity of P100.

Those factors responsible for the differences seen between the parent and vaccine strain are not known. It has been shown in studies with the mammalian reoviruses that upon infection, virions enter cells where they are partially uncoated, triggering the activation of the endogenous transcriptase (Ramig and Fields, 1977; Spandidos and Graham, 1976). Uncoating or unmasking of the transcriptase is initiated by the complete loss of polypeptides $\sigma_{1}$ and $\sigma_{3}$ and partial cleavage of $\mu_{1 \mathrm{C}}$ (Joklik, 1981). Although correlations between the mammalian and avian reovirus polypeptides have not yet been made conclusively, preliminary observations have led to assignments of the avian polypeptides $\sigma_{\mathrm{C}}, \sigma_{\mathrm{B}}$, and $\mu_{\mathrm{B}}$ to polypeptides $\sigma_{1}, \sigma_{3}$, and $\mu_{1 \mathrm{C}}$ of the mammalian reovirus, respectively (Schnitzer et $a l$., 1982). It is of note that the $\sigma_{\mathrm{C}}, \sigma_{\mathrm{B}}$, and $\mu_{\mathrm{B}}$ proteins were found in P100 to have altered mobility by PAGE $\left(\sigma_{\mathrm{C}}\right.$ and $\left.\mu_{\mathrm{B}}\right)$ or altered stability $\left(\sigma_{\mathrm{B}}\right)$ when compared to homologous polypeptides of wild-type S1133 virus. It is possible that the alterations in these proteins may have contributed to the observations made in this study.

Further work needs to be done to define with the avian reoviruses the functions of the individual genes and their respective protein products during viral replication. By the production and analysis of reassortant viruses, utilizing both $\mathrm{P} 100$ and S1133 in combination with another appropriately selected avian reovirus strain, it should be possible to determine which gene or genes of P100 are important for both the biological as well as biochemical differences seen in comparison to S1133. Furthermore, in vitro hybridization analyses can directly examine gene alterations between these two viruses. In this way, the mechanism behind the differences in behavior of $\mathrm{S} 1133$ and $\mathrm{P} 100$ at 37 and $41^{\circ}$ might be determined, yielding better insights into the effects these strains exert on their host.

\section{ACKNOWLEDGMENTS}

This work was supported by a grant from the Kroc Foundation and United States Public Health Service Research Grant R01 AM 27521-02 and Multipurpose Arthritis Center Grant AM 20557-05 from the National Institutes of Health. T. J. Schnitzer is a Senior Investigator of the Arthritis Foundation, and V. G. was supported in part by a fellowship $(2610 / 76)$ from CAPES, Brazil.

\section{REFERENCES}

Gershowitz, A., and Wooley, R. W. (1973). Characterization of two reoviruses isolated from turkeys with infectious enteritis. Avian Dis. 17, 406414.

Glass, S. E., NAGi, S. A., HALL, C. F., and KeRR, K. M. (1973). Isolation and characterization of a virus associated with arthritis of chickens. Avian Dis. 17, 415-424.

Gouvea, V. S., and Schnitzer, T. J. (1982). Pathogenicity of avian reoviruses: Examination of six isolates and a vaccine strain. Infect. Immun. 38, 731-738.

Gouvea, V. S., and Schnitzer, T. J. (1982). Polymorphism of the genomic RNA's among the avian reoviruses. J. Gen. Virol. 61, 87-91.

JoKLIK, W. (1981). Structure and function of the reovirus genome. Microbiol. Rev. 45, 483-501.

MaAssab, H. F., MonTo, A. S., DeBorde, D. C., CoX, N. J., and KENDAL, A. P. (1981). Development of cold recombinants of influenza virus as live virus vaccines. In "Genetic Variation among Influenza Viruses" (D. P. Nayak, ed.), pp. 617-637. Academic Press, New York.

Murphy, B. R., Chalhub, E. G., Nusinoff, S. R., and CHaNock, R. M. (1972). Temperature-sensitive mutants of influenza virus. II. Attenuation of ts recombinants for man. J. Infect. Dis. 125, 176-178. 
OLson, N. O. (1959). Transmissible synovitis of poultry. Lab. Invest. 8, 1384-1393.

OLSON, N. O. (1978). Reovirus infections. In "Diseases of Poultry" (M. S. Hofstad, ed.), pp. 641-647. Iowa State Univ. Press, Ames.

Olson, N. O., and Solomon, D. P. (1968). A natural outbreak of synovitis caused by the viral arthritis agent. Avian Dis. 12, 311-316.

RAMIG, F. R., and FIELDS, B. N. (1977). Reoviruses. In "The Molecular Biology of Animal Viruses" (D. P. Nayak, ed.), Vol. 1, pp. 383-433. Dekker, New York.

RaU, W. E., van DER Heide, L., Kalbac, M., and GIRSHICK, T. (1980). Onset of progeny immunity against viral arthritis/tenosynovitis after experimental vaccination of parent breeder chickens and crossimmunity against six reovirus isolates. Avian Dis. 24, 648-657.

Sammons, D. W., Adams, L. D., and Nishizawa, E. E. (1981). Ultrasensitive silver-based color staining of polypeptides in polyacrylamide gels. Electrophoresis 2, 135-141.

Schnitzer, T. J., Ramos, T., and Gouvea, V. S. (1982).
Avian reovirus polypeptides: Analysis of intracellular virus-specified products, virions, top component, and cores. J. Virol 43, 1006-1014.

Spandidos, D. A., and GrahaM, A. F. (1976). Nonpermissive infection of $L$ cells by an avian reovirus: Restricted transcription of the viral genome. $J$. Virol. 19, 977-984.

VAN DER HEIDE, L. (1975). Infectious tenosynovitis: Immunization experiments with a viral isolate. Clin. Vet. 98, 409-413.

VAN DER HEIDE, L. (1977). Viral arthritis/tenosynovitis: A review. Avian Pathol 6, 271-284.

VAN DER HEIDE, L. (1980). Development of attenuated day-old chick vaccine against viral arthritis/tenosynovitis in chickens. J. Amer. Vet. Med. Assoc. 177, 258.

Wright, P. F., Muls V. J., and Chanock, R. M. (1971). Evaluation of a temperature-sensitive mutant of respiratory synctial virus in adults. $J$. Infect. Dis. 124, 505-511.

Wanatabe, Y., Millward, S., and Graham, A. F. (1978). Regulation of transcription of the reovirus genome. J. Mol. Biol. 36, 107-123. 